\title{
Applicant gender and matching to first-choice discipline: a cross-sectional analysis of data from the Canadian Resident Matching Service (2013-2019)
}

\author{
Shannon M. Ruzycki MD MPH, Madalene Earp PhD, Irene W.Y. Ma MD PhD
}

Abstract

Background: Previous studies examining potential sex and gender bias in the Canadian Resident Matching Service (CaRMS) match have had conflicting results. We examined the results of the CaRMS match over the period 2013-2019 to determine the potential association between applicants' gender and the outcome of matching to their first-choice discipline.

Methods: In this cross-sectional analysis, we determined the risk of matching to one's first-choice discipline in CaRMS by applicant gender and year, for all Canadian medical students who participated in the first iteration of the R-1 match for the years 2013 to 2019. We analyzed data in 3 categories of disciplines according to CaRMS classifications: family medicine, nonsurgical disciplines and surgical disciplines. We excluded disciplines with fewer than 10 applicants.

Results: Match results were available for 20033 participants, of whom 11078 (55.3\%) were female. Overall, female applicants were significantly more likely to match to their first-choice discipline (relative risk [RR] 1.03, 95\% confidence interval [Cl] 1.02-1.04). After adjustment for match year and stratification by discipline categories, we found that female applicants were more likely to match to family medicine as their first choice (RR 1.04, 95\% Cl 1.03-1.05) and less likely to match to a first-choice surgical discipline (RR $0.95,95 \% \mathrm{Cl} 0.91-1.00$ ) than their male peers. There was no significant difference between the genders in matching to one's first-choice nonsurgical discipline (RR 1.01, 95\% Cl 0.99-1.03).

Interpretation: These results suggest an association between an applicant's gender and the probability of matching to one's firstchoice discipline. The possibility of gender bias in the application process for residency programs should be further evaluated and monitored.

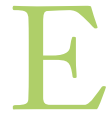
ach year, the Canadian Resident Matching Service (CaRMS) administers a matching process whereby eligible applicants apply for and are assigned to Canadian residency positions. ${ }^{1}$ The CaRMS match is intended to be a "fair, transparent, and equitable" process that favours the applicant. ${ }^{2,3}$ Published best practices in residency application recommend that resident selection should promote diversity and "be free of inappropriate bias." Despite these recommendations, the CaRMS match has recently been criticized for its subjectivity and possible bias. 4,5 These concerns are compounded by recent increases in the number of unmatched applicants; as the match becomes more competitive, potential biases may affect larger numbers of medical students. ${ }^{1,4,5}$

Previous attempts to monitor North American resident matches for gender bias have had disparate results. Several observational studies of small programs have not found evidence of gender or sex bias, ${ }^{6,7}$ whereas others have reported an advantage for female applicants. ${ }^{8,9}$ A series of articles evaluating CaRMS match data from 1995 to 2004 found no advantage for either male or female applicants when applying to various surgical specialties, an overall disadvantage for male applicants when all specialties were combined, and an advantage for female applicants when the first-choice specialty was psychiatry, family medicine or emergency medicine. ${ }^{9-12}$ However, a recent letter to the editor concerning the 2018 CaRMS match suggested that a lower proportion of women than men matched to their first-choice discipline in the surgical specialties. ${ }^{5}$

Detailed analysis of the association between matching to one's top-ranked discipline in CaRMS and the applicant's gender has not been reported since 2004. An up-to-date

Competing interests: None declared.

This article has been peer reviewed.

Correspondence to: Shannon Ruzycki, shannon.ruzycki@ucalgary.ca CMAJ Open 2020. DOI:10.9778/cmajo.20190029 
analysis of the CaRMS match results is needed to better understand whether gender bias may be present in more recent matches. We therefore assessed variability in firstchoice match rates between male and female applicants from Canadian medical schools in the 2013 through 2019 CaRMS match.

\section{Methods}

\section{Setting and design}

For this cross-sectional analysis, we used results from the CaRMS first-iteration R-1 match for the years 2013 to 2019. We excluded disciplines with fewer than 10 applicants over the study period because of small numbers, and we also excluded family medicine integrated specialties because it was unclear how these disciplines should be categorized.

\section{Data source}

We obtained data from CaRMS for the first iteration of the R-1 match for the years 2013 to 2019, regardless of match status. In the CaRMS match, medical students submit applications to training programs, ranking their programs in order of preference, and the training programs similarly rank the applicants (a detailed description of the CaRMS match algorithm is available in video format ${ }^{3}$ ). The residency training programs have access to a photograph of the applicant, the applicant's name and gender identity (binary options only), and supporting documents, such as medical school transcripts and student performance records, citizenship documents, reference letters, personal letters, and examination results and assessments. The CaRMS algorithm then matches each applicant to the highest-ranked program for which spots are still available, moving down the applicant's list until the applicant has a position or is left unmatched. Unmatched candidates may then participate in the second iteration of CaRMS, during which they may apply for any unfilled residency positions. ${ }^{3}$ We obtained data for Canadian medical graduates concerning their first-choice discipline and matched discipline, as well as the number of applicants who matched to their first-choice discipline, segregated by gender. Data on geographic location of matches, including firstchoice geographic location, were not available because of privacy standards.

CaRMS has defined the following discipline groupings: family medicine, nonsurgical and surgical. The surgical disciplines were cardiac surgery, general surgery, neurosurgery, obstetrics and gynecology, ophthalmology, orthopedic surgery, otolaryngology, plastic surgery, urology and vascular surgery. The nonsurgical disciplines were anatomic pathology, anesthesiology, dermatology, diagnostic radiology, emergency medicine, general pathology, hematologic pathology, internal medicine, laboratory medicine, medical genetics, medical microbiology, neurology, neurology - pediatric, neuropathology, nuclear medicine, pediatrics, physical medicine and rehabilitation, psychiatry, public health and preventive medicine, and radiation oncology. ${ }^{13}$ Gender was self-reported, and the only options offered on the CaRMS application are "male" and "female."

\section{Statistical analysis}

We assessed univariable associations with $\chi^{2}$ statistics. We analyzed associations between matching to one's first-choice discipline and gender, discipline and match year using multivariable log-binomial regression. We grouped the disciplines according to the CaRMS-defined groupings: family medicine, nonsurgical and surgical. We report the relative risk (RR) of matching to one's first-choice specialty using male gender as the reference gender, 2013 as the reference year and family medicine as the reference discipline. We assessed effect modification by including interaction terms for each of the variables and assessing their significance (defined as $p<0.05$ ) in the model.

We conducted secondary analyses on 31 individual CaRMS disciplines, and analyzed the relative risk of matching in each individual discipline by gender using bivariable analysis, pooling data across years. For this analysis, we report the fixed-effects (Mantel-Haenszel) summary RR. All statistical analyses were conducted using $\mathrm{R}$ version 3.6.0.

\section{Ethics approval}

This study was approved by the University of Calgary's institutional ethics review board.

\section{Results}

\section{Study cohort}

Applicant gender, first-choice discipline and match results were available for 20058 participants for the match years from 2013 to 2019 ( $n=11090$ women [55.3\%]). Two disciplines with a total of 25 participants ( $0.1 \%$ of the total cohort; $n=12$ women [48\%]) were excluded from analysis. Excluded disciplines are listed in Appendix 1 (available at www.cmajopen.ca/ content/8/2/E346/suppl/DC1).

Table 1 presents cohort characteristics stratified by the 3 discipline categories. There were 7144 applicants who ranked family medicine as their first choice $(n=4455$ women [62.4\%]), 9298 applicants who ranked nonsurgical disciplines as their first choice $(n=4775$ women [51.4\%]) and 3591 applicants who ranked surgical disciplines as their first choice $(n=1848$ women [51.5\%]). A greater proportion of female than male applicants ranked family medicine as their first-choice discipline (40.2\% v. $30.0 \%)$ and a lower proportion of female than male applicants ranked a surgical discipline as their first choice (16.7\% v. $19.5 \%)$.

\section{Matching to first-choice discipline}

Overall, $16766(83.7 \%)$ of applicants matched to their firstchoice discipline during the study period (Table 2). The proportion of applicants matching to their first-choice discipline was lowest for surgical disciplines $(69.1 \%, n=2481)$ and highest for family medicine $(96.3 \%, n=6881)(p<$ $0.001)$. Overall, a greater proportion of female than male applicants matched to their first-choice discipline $(84.9 \% \mathrm{v}$. $82.2 \%$; absolute difference $+2.7 \%$; $p<0.001$ ). With stratification by discipline category, a significantly greater proportion of female than male applicants matched to family medicine as a first choice $(97.6 \%$ v. $94.2 \%$; absolute difference 
Research

\begin{tabular}{|c|c|c|c|c|}
\hline Factor & All disciplines & Family medicine & Nonsurgical disciplines $†$ & Surgical disciplinesł \\
\hline Overall & $20033(100.0)$ & $7144(35.7)$ & $9298(46.4)$ & 3591 (17.9) \\
\hline \multicolumn{5}{|l|}{ Gender } \\
\hline \multicolumn{5}{|l|}{ Match year } \\
\hline 2013 & 2695 & 979 (36.3) & 1167 (43.3) & $549(20.4)$ \\
\hline 2014 & 2847 & $1087(38.2)$ & $1275(44.8)$ & $485(17.0)$ \\
\hline 2015 & 2862 & $1101(38.5)$ & $1290(45.1)$ & $471(16.4)$ \\
\hline 2019 & 2919 & 974 (33.4) & $1436(49.2)$ & $509(17.4)$ \\
\hline \multicolumn{5}{|c|}{$\begin{array}{l}\text { *For overall data (first row) and data according to match year, the percentages are calculated by row only. } \\
\text { †Anatomic pathology, anesthesiology, dermatology, diagnostic radiology, emergency medicine, general pathology, hematologic pathology, internal medicine, laboratory } \\
\text { medicine, medical genetics, medical microbiology, neurology, neurology - pediatric, neuropathology, nuclear medicine, pediatrics, physical medicine and rehabilitation, } \\
\text { psychiatry, public health and preventive medicine, and radiation oncology. } \\
\text { łCardiac surgery, general surgery, neurosurgery, obstetrics and gynecology, ophthalmology, orthopedic surgery, otolaryngology, plastic surgery, urology and vascular surgery }\end{array}$} \\
\hline
\end{tabular}

Table 2: Number and proportion of applicants who matched to their first-choice discipline according to study factors, for the overall cohort and stratified by 3-category discipline

\begin{tabular}{|c|c|c|c|c|c|}
\hline \multirow[b]{2}{*}{ Factor } & \multicolumn{4}{|c|}{ Discipline category; no. (\%) of applicants* } & \multirow[b]{2}{*}{$p$ value§ } \\
\hline & All disciplines & Family medicine & $\begin{array}{l}\text { Nonsurgical } \\
\text { disciplines† }\end{array}$ & $\begin{array}{c}\text { Surgical } \\
\text { disciplines }\end{array}$ & \\
\hline $\begin{array}{l}\text { Applicants matched to } \\
\text { first-choice discipline }\end{array}$ & $16766(83.7)$ & $6881(96.3)$ & $7404(79.6)$ & $2481(69.1)$ & \\
\hline Gender & & & & & Overall: $p<0.001$ \\
\hline Female & $9406(84.9)$ & $4349(97.6)$ & $3813(79.9)$ & $1244(67.3)$ & $\begin{array}{c}\text { Female v. male: } \\
p_{\text {Family }}<0.001 \\
p_{\text {Nonsurgical }}=0.6 \\
p_{\text {Surgical }}=0.02\end{array}$ \\
\hline Male & $7360(82.2)$ & $2532(94.2)$ & $3591(79.4)$ & $1237(71.0)$ & \\
\hline Year & & & & & Overall: $p<0.001$ \\
\hline 2013 & $2333(86.6)$ & $948(96.8)$ & $994(85.2)$ & $391(71.2)$ & $\begin{array}{c}2013-2019: \\
p_{\text {Family }}=0.8 \\
p_{\text {Nonsurgical }}<0.001 \\
p_{\text {Surgical }}<0.001\end{array}$ \\
\hline 2014 & $2461(86.4)$ & $1038(95.5)$ & $1059(83.1)$ & $364(75.1)$ & \\
\hline 2015 & $2454(85.7)$ & $1060(96.3)$ & $1040(80.6)$ & $354(75.2)$ & \\
\hline 2016 & $2428(83.6)$ & $1013(96.5)$ & $1066(78.4)$ & $349(70.5)$ & \\
\hline 2017 & $2364(81.7)$ & $950(96.6)$ & $1073(76.7)$ & $341(66.7)$ & \\
\hline 2018 & 2341 (80.4) & $935(96.4)$ & 1070 (78.0) & $336(58.8)$ & \\
\hline 2019 & $2385(81.7)$ & 937 (96.2) & $1102(76.7)$ & $346(68.0)$ & \\
\hline $\begin{array}{l}\text { *The denominators for calcu } \\
\dagger \text { Anatomic pathology, anestl } \\
\text { medicine, medical genetics, } \\
\text { psychiatry, public health and } \\
\text { †Cardiac surgery, general su } \\
\S \text { The } p \text { values are based on }\end{array}$ & $\begin{array}{l}\text { centages in this t } \\
\text { dermatology, dia } \\
\text { nicrobiology, neu } \\
\text { e medicine, and } \\
\text { urosurgery, obste } \\
\text { st. }\end{array}$ & $\begin{array}{l}\text { e the values in the co } \\
\text { radiology, emergenc } \\
\text { neurology - pediatric } \\
\text { on oncology. } \\
\text { d gynecology, ophtha }\end{array}$ & $\begin{array}{l}\text { ling cells of Table } \\
\text { ne, general pathol } \\
\text { athology, nuclear n } \\
\text { orthopedic surger }\end{array}$ & $\begin{array}{l}\text { tologic pathology } \\
\text { ediatrics, physice } \\
\text { yology, plastic sur }\end{array}$ & $\begin{array}{l}\text { medicine, laboratory } \\
\text { ee and rehabilitation, } \\
\text { logy and vascular surgery. }\end{array}$ \\
\hline
\end{tabular}


$+3.4 \% ; p<0.001)$, but a significantly lower proportion matched to a first-choice surgical discipline $(67.3 \% \mathrm{v}$. $71.0 \%$; absolute difference $-3.7 \% ; p=0.02$ ).

After adjustment for match year and discipline, female gender was associated with matching to one's first-choice discipline (RR 1.03, 95\% confidence interval [CI] 1.02-1.04; Table 3). Relative to 2013, matching to one's first-choice discipline was less likely in 2018 and 2019; this finding was primarily driven by greater risk of not matching to one's first choice in nonsurgical disciplines. Compared with applicants who ranked family medicine as their first choice, applicants who ranked nonsurgical and surgical disciplines as their first choice were $17 \%$ and $28 \%$ less likely to match, respectively (RR for nonsurgical disciplines 0.83 , 95\% CI 0.82-0.84; RR for surgical disciplines $0.72,95 \%$ CI 0.70-0.74).

\section{Interaction of gender and matching to first-choice discipline}

Discipline and gender were the only statistically significant interaction terms. Therefore, we performed log-binomial regression analyses stratified by discipline (Table 3). In the stratified analyses, gender was significantly associated with matching to one's first-choice discipline (Table 3). Female applicants were significantly less likely than male applicants to match to a first-choice surgical discipline (RR 0.95, 95\% CI 0.91-1.00). In contrast, female applicants were significantly more likely to match to family medicine as a first choice (RR 1.04, 95\% CI 1.03-1.05). There was no association of gender with matching to a first-choice nonsurgical specialty (RR 1.01, 95\% CI 0.99-1.03).

We assessed the relative risk of matching to one's first choice in 31 individual disciplines by gender using bivariable analysis (i.e., pooling data across years; Table 4). We did not perform multivariable regression for the 31 disciplines because of small sample size for many of the individual disciplines. Female applicants were significantly less likely to match to urology than their male peers (RR for urology 0.80, 95\% CI 0.66-0.97) and significantly more likely to match to psychiatry and family medicine as their first choice (RR for psychiatry $1.06,95 \%$ CI 1.01-1.11; RR for family medicine $1.04,95 \%$ CI $1.03-1.05)$.

\section{Interpretation}

Our study provides an assessment of the association between applicant gender and matching to one's first-choice

\begin{tabular}{|c|c|c|c|c|}
\hline \multirow[b]{2}{*}{ Variable } & \multirow{2}{*}{$\begin{array}{l}\text { RR }(95 \% \mathrm{Cl}) \text { for } \\
\text { unstratified } \\
\text { adjusted model* }\end{array}$} & \multicolumn{3}{|c|}{ Discipline category; RR $(95 \% \mathrm{Cl})$ for stratified adjusted model† } \\
\hline & & Family medicine & $\begin{array}{l}\text { Nonsurgical } \\
\text { disciplinesł }\end{array}$ & $\begin{array}{c}\text { Surgical } \\
\text { disciplines§ }\end{array}$ \\
\hline Total no. of applicants & 20033 & 7144 & 9298 & 3591 \\
\hline \multicolumn{5}{|l|}{ Gender } \\
\hline Male & 1.0 (Ref.) & 1.0 (Ref.) & 1.0 (Ref.) & 1.0 (Ref.) \\
\hline Female & $1.03(1.02-1.04)$ & $1.04(1.03-1.05)$ & $1.01(0.99-1.03)$ & $0.95(0.91-1.00)$ \\
\hline \multicolumn{5}{|l|}{ Year } \\
\hline 2013 & 1.0 (Ref.) & 1.0 (Ref.) & 1.0 (Ref.) & 1.0 (Ref.) \\
\hline 2014 & $0.99(0.98-1.00)$ & $0.99(0.97-1.00)$ & $0.98(0.94-1.01)$ & $1.05(0.98-1.13)$ \\
\hline 2015 & $0.99(0.98-1.00)$ & $1.00(0.98-1.01)$ & $0.95(0.91-0.98)$ & $1.06(0.98-1.14)$ \\
\hline 2016 & $0.99(0.97-1.00)$ & $1.00(0.98-1.01)$ & $0.92(0.89-0.96)$ & $0.99(0.92-1.07)$ \\
\hline 2017 & $0.98(0.97-1.00)$ & $1.00(0.98-1.01)$ & $0.90(0.87-0.94)$ & $0.94(0.87-1.02)$ \\
\hline 2018 & $0.98(0.96-0.99)$ & $1.00(0.98-1.01)$ & $0.92(0.88-0.95)$ & $0.83(0.76-0.90)$ \\
\hline 2019 & $0.98(0.96-0.99)$ & $0.99(0.98-1.00)$ & $0.90(0.87-0.94)$ & $0.96(0.88-1.04)$ \\
\hline \multicolumn{5}{|l|}{ Discipline } \\
\hline Family medicine & 1.0 (Ref.) & - & - & - \\
\hline Nonsurgicalł & $0.83(0.82-0.84)$ & - & - & - \\
\hline Surgical§ & $0.72(0.70-0.74)$ & - & - & - \\
\hline \multicolumn{5}{|c|}{$\begin{array}{l}\text { Note: } \mathrm{Cl}=\text { confidence interval, Ref. = reference category, RR = relative risk. } \\
\text { *Controlled for gender, year (categorical) and 3-category discipline, with no interaction terms. } \\
\text { tControlled for gender and year (categorical). } \\
\text { fAnatomic pathology, anesthesiology, dermatology, diagnostic radiology, emergency medicine, general pathology, hematologic pathology, } \\
\text { internal medicine, laboratory medicine, medical genetics, medical microbiology, neurology, neurology - pediatric, neuropathology, nuclear } \\
\text { medicine, pediatrics, physical medicine and rehabilitation, psychiatry, public health and preventive medicine, and radiation oncology. } \\
\text { §Cardiac surgery, general surgery, neurosurgery, obstetrics and gynecology, ophthalmology, orthopedic surgery, otolaryngology, plastic } \\
\text { surgery, urology and vascular surgery. }\end{array}$} \\
\hline
\end{tabular}




\begin{tabular}{|c|c|}
\hline Discipline & $\mathrm{RR}(95 \% \mathrm{Cl})^{*}$ \\
\hline Family medicine & $1.04(1.03-1.05)$ \\
\hline \multicolumn{2}{|l|}{ Nonsurgical disciplines† } \\
\hline Anatomic pathology & $1.08(0.99-1.17)$ \\
\hline Anesthesiology & $1.00(0.93-1.09)$ \\
\hline Dermatology & $0.96(0.79-1.18)$ \\
\hline Diagnostic radiology & $1.00(0.93-1.09)$ \\
\hline Emergency medicine & $1.04(0.92-1.17)$ \\
\hline General pathology & $1.02(0.68-1.52)$ \\
\hline Hematologic pathology & $0.86(0.63-1.16)$ \\
\hline Internal medicine & $1.01(0.98-1.03)$ \\
\hline Laboratory medicine & $1.22(0.93-1.61)$ \\
\hline Medical genetics (and genomics) & $1.09(0.92-1.29)$ \\
\hline Medical microbiology & $1.00(0.68-1.46)$ \\
\hline Neurology & $1.08(0.97-1.20)$ \\
\hline Neurology - pediatric & $0.99(0.65-1.49)$ \\
\hline Neuropathology & $1.00(1.00-1.00)$ \\
\hline Nuclear medicine & $1.22(1.00-1.49)$ \\
\hline Pediatrics & $1.02(0.94-1.11)$ \\
\hline Physical medicine and rehabilitation & $1.03(0.89-1.19)$ \\
\hline Psychiatry & $1.06(1.01-1.11)$ \\
\hline Public health and preventive medicine & $1.11(0.88-1.38)$ \\
\hline Radiation oncology & $0.98(0.86-1.12)$ \\
\hline \multicolumn{2}{|l|}{ Surgical disciplines $†$} \\
\hline Cardiac surgery & $0.82(0.61-1.11)$ \\
\hline General surgery & $0.99(0.91-1.08)$ \\
\hline Neurosurgery & $0.97(0.76-1.24)$ \\
\hline Obstetrics and gynecology & $0.98(0.86-1.11)$ \\
\hline Ophthalmology & $1.04(0.90-1.20)$ \\
\hline Orthopedic surgery & $0.96(0.87-1.06)$ \\
\hline Otolaryngology & $0.89(0.75-1.06)$ \\
\hline Plastic surgery & $0.94(0.75-1.17)$ \\
\hline Urology & $0.80(0.66-0.97)$ \\
\hline Vascular surgery & $0.83(0.59-1.15)$ \\
\hline Summary & $1.02(1.01-1.03)$ \\
\hline \multicolumn{2}{|c|}{$\begin{array}{l}\text { Note: } \mathrm{Cl}=\text { confidence interval, } \mathrm{RR}=\text { relative risk. } \\
{ }^{*} \text { Data are pooled across years. } \\
\text { †As defined by the Canadian Resident Matching Service. } \\
\text { †Fixed effects (Mantel-Haenszel) meta-analysis. }\end{array}$} \\
\hline
\end{tabular}

discipline in the CaRMS matches over the period 2013 to 2019. In our study, female applicants were more likely overall to match to their first-choice discipline than male applicants. However, we also found that male applicants were significantly more likely to match to their first-choice surgical discipline than female applicants and, conversely, that female applicants were significantly more likely to match to family medicine as a first choice.

Previous examinations of the effect of sex or gender on successful matching to residency training program have had conflicting results. In an audit of a single anesthesiology training program in the United States, female applicants were more likely to match than male applicants (odds ratio [OR] 1.2, 95\% CI 1.1-1.3). ${ }^{8}$ Similarly, in the combined CaRMS matches for 1995 to 2004, male applicants had 1.6 greater odds of being unmatched than female applicants. ${ }^{9}$ The latter authors did not find a significant association of sex or gender with odds of matching to radiology, ophthalmology or the surgical specialties. ${ }^{10-12}$ A study of a single US radiology training program determined that female applicants were more likely to receive an interview than male candidates, but female applicants were no more likely to match than male applicants. ${ }^{7}$ Worryingly, a recently published study of neurosurgery applicants in the US National Resident Matching Program between 1990 and 2007 showed that female candidates were less likely to match than their male counterparts (OR 0.59, 95\% CI 0.48-0.72), even after adjustment for confounders such as United States Medical Licensing Examination scores and medical school class rank. ${ }^{14}$ In contrast, a well-designed single-centre study that used randomly assigned names for orthopedic surgery applications did not detect implicit gender bias. ${ }^{15}$ Importantly, although multiple studies have been performed to examine factors that may influence match results, many have not reported on the impact of applicant sex or gender. ${ }^{16,17}$

\section{Limitations}

An important limitation of our study is that CaRMS data do not provide information on the strength of individual applications, according to aspects such as an applicant's performance records ${ }^{18}$ and the quality of reference letters. ${ }^{6}$ In addition, CaRMS does not collect data on other potential confounders that might influence an applicant's success, such as age, race or ethnicity, indigeneity, sexual orientation, ${ }^{8,19}$ personality characteristics ${ }^{20}$ or a parent's career. ${ }^{21}$ The absence of these data types limited our ability to address intersectionality, that is, the overlap of social categories that combine to increase or alter how disadvantage or discrimination is experienced by specific groups. For example, systemic disadvantages experienced by women from racial minorities in medicine are expected to be greater than and different from those faced by white women or men from racial minorities. In addition, CaRMS collects data on applicant gender only in binary categories, which prevented us from assessing the impact of applicant gender on match results, in particular for applicants who are gender diverse or gender nonconforming.

Our selected outcome - matching to one's first-choice discipline - might miss other outcomes considered important by candidates. For example, applicants might consider their first-choice city for training to be more important than their discipline or might consider their second-choice discipline to be highly acceptable. 
Our study analyzed data only for Canadian medical graduates undergoing the first iteration of the CaRMS match. Our results may not be generalizable beyond this population.

Given the number of statistical analyses that we performed, such as those reported in Table 4, our results are subject to risks from multiple comparisons and type 1 errors. Therefore, these results should be interpreted with caution.

Our results also do not account for specific program efforts that may have been undertaken during the study period, such as implicit-bias training. Such efforts may affect gender bias. ${ }^{22,23}$

\section{Conclusion}

Our findings have important implications. The CaRMS match is a career branch point for Canadian physicians. Residency training programs therefore have a responsibility to ensure that their application processes are objective and fair, and it is of ethical and legal importance to monitor the matching process for bias and to implement effective systemic methods to reduce or eliminate bias. The potential presence of bias in the CaRMS match warrants greater attention and additional evaluation. Failure to guard residency selection from bias invites legal and ethical scrutiny.

\section{References}

1. Wilson CR, Bordman ZN. What to do about the Canadian Resident Matching Service. CMA7 2017;189:E1436-47.

2. Canadian Resident Matching Service [homepage]. Ottawa: Canadian Resident Matching Service. Available: www.carms.ca (accessed 2020 Feb. 24).

3. How does the match algorithm work? [video]. Ottawa: Canadian Resident Matching Service. Available: www.carms.ca/the-match/how-it-works/ (accessed 2020 Feb. 24).

4. Bandiera G, Abrahams C, Ruetalo M, et al. Identifying and promoting best practices in residency application and selection in a complex academic health network. Acad Med 2015;90:1594-601.

5. Ryan T. Addressing bias and lack of objectivity in the Canadian resident matching process [letter]. CMA7 2018;190:E1211-2.

6. Fraser JD, Aguayo P, St Peter S, et al. Analysis of the pediatric surgery match: factors predicting outcome. Pediatr Surg Int 2011;27:1239-44.

7. Hewett L, Lewis M, Collins $\mathrm{H}$, et al. Gender bias in diagnostic radiology resident selection, does it exist? Acad Radiol 2016;23:101-7.

8. de Oliveira GS Jr, Akikwala T, Kendall MC, et al. Factors affecting admission to anesthesiology residency in the United States: choosing the future of our specialty. Anesthesiology 2012;117:243-51.

9. Baerlocher MO, Detsky AS. Are applicants to Canadian residency programs rejected because of their sex? CMA7 2005;173:1439-40.

10. Baerlocher MO. Does sex affect residency application to surgery? Can 7 Surg 2007;50:434-6.

11. Baerlocher MO, Noble J. Does sex affect the success rate of Canadian ophthalmology residency applicants? Can 7 Ophthalmol 2006;41:163-8
12. Baerlocher MO, Walker M. Does gender impact upon application rejection rate among Canadian radiology residency applicants? Can Assoc Radiol 7 2005;56:232-7.

13. R-1 data and reports. Ottawa: Canadian Resident Matching Service; 2019. Available: www.carms.ca/data-reports/r1-data-reports/ (accessed 2020 Feb. 24).

14. Durham SR, Donaldson K, Grady MS, et al. Analysis of the 1990-2007 neurosurgery residency match: Does applicant gender affect neurosurgery match outcome? 7 Neurosurg 2018;129:282-9.

15. Scherl SA, Lively N, Simon MA. Initial review of Electronic Residency Application Service charts by orthopaedic residency faculty members. Does applicant gender matter? 7 Bone foint Surg Am 2001;83:65-70.

16. Collins M, Curtis A, Artis K, et al. Comparison of two methods for ranking applicants for residency. $7 \mathrm{Am}$ Coll Radiol 2010;7:961-6.

17. Stratman EJ, Ness RM. Factors associated with successful matching to dermatology residency programs by reapplicants and other applicants who previously graduated from medical school. Arch Dermatol 2011;147:196-202.

18. Mueller AS, Jenkins TM, Osborne M, et al. Gender differences in attending physicians' feedback to residents: a qualitative analysis. 7 Grad Med Educ 2017; 9:577-85.

19. Criminal Code, R.S.C. 1985 , c. C-46.

20. Frantsve LM, Laskin DM, Auerbach SM. Personality and gender influences on faculty ratings and rankings of oral and maxillofacial surgery residency applicants. 7 Dent Educ 2003;67:1252-9.

21. Weissbart SJ, Stock JA, Wein AJ. Program directors' criteria for selection into urology residency. Urology 2015;85:731-6.

22. Devine PG, Forscher PS, Cox WTL, et al. A gender bias habit-breaking intervention led to increased hiring of female faculty in STEMM departments. 7 Exp Soc Psychol 2017;73:211-5

23. Girod S, Fassiotto M, Grewal D, et al. Reducing implicit gender leadership bias in academic medicine with an educational intervention. Acad Med 2016;91:1143-50

Affiliations: Division of General Internal Medicine, Department of Medicine (Ruzycki, Ma), Department of Community Health Sciences (Ruzycki) and Department of Oncology (Earp), Cumming School of Medicine, University of Calgary, Calgary, Alta.

Contributors: Shannon Ruzycki conceived and designed the project, contributed to data acquisition and analysis, wrote the first draft of the manuscript and edited all versions of the manuscript. Madalene Earp performed the data analysis, contributed to the methods, results and tables, and edited the revised manuscript. Irene $\mathrm{Ma}$ supervised this work, provided administrative and funding support, contributed to the study design and data analysis, and edited the first draft and revised versions of the manuscript. All authors gave final approval of the version to be published and agreed to act as guarantors of the work.

Funding: This study was funded by the John A. Buchanan Chair of General Internal Medicine at the University of Calgary.

Data sharing: The data used in this study are publicly available at the website of the Canadian Resident Matching Service (www.carms.ca/), under the "Data \& Reports" tab.

Acknowledgements: The authors thank Sara Rattanasithy and the data services team of the Canadian Resident Matching Service for providing and preparing the data used in this study.

Supplemental information: For reviewer comments and the original submission of this manuscript, please see www.cmajopen.ca/content/8/2/ E346/suppl/DC1. 